\title{
Understanding Space Weather Customers in GPS-Reliant Industries
}

\author{
Jennifer Meehan, Genene Fisher, and William Murtagh
}

Published 10 June 2010.

Citation: Meehan, J., G. Fisher, and W. Murtagh (2010), Understanding Space Weather Customers in GPS-Reliant Industries, Space Weather, 8, S06003, doi:10.1029/2009SW000556.

Since the last solar maximum, society has become extremely reliant on the Global Positioning System (GPS), which is often referred to as the "fourth utility" behind electricity, water, and natural gas. As the economy depends more and more on positioning, navigation, and timing, society's vulnerability to space weather continues to increase because space weather can be a significant cause of GPS errors. Critical applications such as railway control, highway traffic management, precision agriculture, emergency response, commercial aviation, and marine navigation all require GPS services. With such widespread and critical usage, industries are becoming more aware of how space weather can affect GPS signals, rapidly increasing the number of customers interested in real-time space weather products and services.

\section{The Surge of GPS}

The first experimental GPS satellite was launched in 1978 by the U.S. Department of Defense (DOD), and the constellation of 24 satellites was completed and declared fully operational in 1995. In 1996 the Clinton administration declared GPS to be a dual-use system and established an interagency GPS executive board to manage it as a national asset. Quickly thereafter, GPS became indispensable for positioning, navigation, and timing by users worldwide. An infrastructure was built and became an engine of economic growth and efficiency as businesses and customers developed new and creative applications of GPS technology, all free of charge.

Today the system provides location and time information for an unlimited number of people, anywhere in the world. Precision GPS quickly became a requirement for numerous applications-timing, transportation, space, agriculture, marine, environment, surveying and mapping, public safety and disaster relief, and recreation. As a consequence, these applications now require real-time knowledge of space weather effects to maintain the integrity of their uses.

\section{Space Weather Products for GPS}

When GPS was first constructed, it was thought to be "undisruptable" and "all weather proof." However, signal disruptions were soon observed, in large part due to the signals' passing through the ionosphere. GPS receivers calculate their locations by analyzing signals from a constellation of satellites, but those signals can be delayed or distorted while passing through the ionosphere. Space weather is by far the largest contributor to single-frequency GPS errors and a significant factor for differential and augmented GPS, which are both techniques for reducing the error in GPS-derived positions by using additional data from a reference GPS receiver at a known position. Single-frequency GPS is more susceptible to GPS ranging errors because only one frequency is being transmitted from a satellite, degrading the ability to directly measure, and therefore remove, the ionospheric delay error for that particular satellite.

The two primary effects of space weather are (1) propagation delay of signals (pseudorange errors) and (2) loss of signal due to scintillation effects caused by small-scale irregularities in the ionosphere. The ionosphere can impose about several tens of meters of positioning error and is often the largest error source for single-frequency applications. During large geomagnetic storms, total electron content (TEC) density gradients in the ionosphere can result in errors of up to 50 meters. GPS errors can also result from solar radio bursts, which can act like noise and interfere with frequencies used by GPS. Recent studies have shown that these large bursts of energy can interrupt GPS signals transmitted to receivers located on the sunlit side of the Earth for tens of minutes.

Such events have raised awareness of GPS vulnerabilities and increased concerns for customers relying on wide-ranging, critical GPS usage. The NOAA Space Weather Prediction Center (SWPC) offers a variety of products for GPS users, including nowcasts of space weather conditions 
over North America. SWPC products include near-real time total electron count (US-TEC), designed to estimate the signal delay for single- and dual-frequency GPS applications, produced every 15 minutes. SWPC also reaches out to its customers, educating them on the effects of space weather. In the past 5 years, SWPC has seen its customer list increase dramatically, even during an extended solar minimum.

\section{Who Are GPS Customers?}

In general, during solar minimum, approximately 250,000 unique customers from 150 countries are accessing data from the SWPC Web site every month. SWPC also provides an electronic mailing list for its customers. Currently more than 600 customers subscribe to the SWPC electronic mailing list for navigation purposes. To better understand the types of customers, the authors performed an analysis to categorize each subscriber according to sector, industry, and application use.

A wide range of GPS users were identified, including communications companies, commercial airlines, federal agencies, public safety offices, emergency responders, financial institutions, environmental services, surveying and mapping companies, consulting firms, and academic institutions.

Figures 1 and 2 show the statistics of subscribers to the SWPC navigation products electronic mailing list as of June

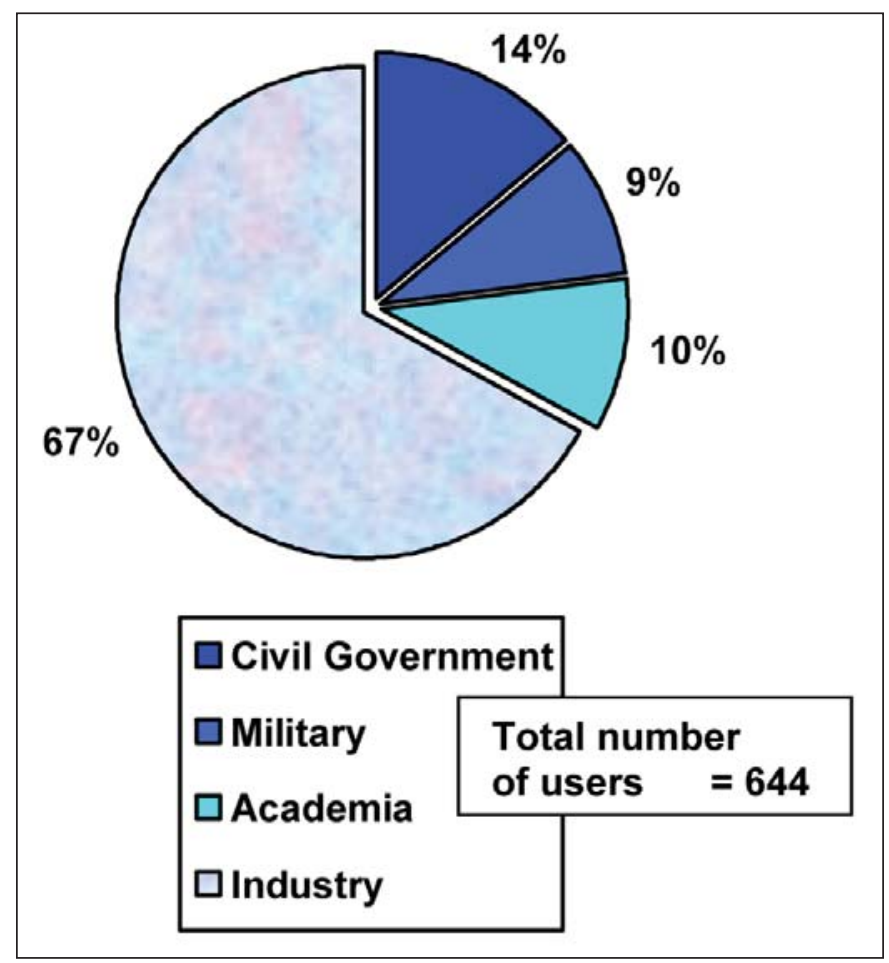

Figure 1. Percentage of Space Weather Prediction Center (SWPC) navigation customers by sector.
2009. Figure 1 shows the customers as a percentage by sector. Civil government (14\%) includes a wide variety of nonmilitary government agencies, both domestic and international. Military (9\%) includes all DOD operations as well as international defense programs. Academia (10\%) includes colleges, universities, K-12 education programs, and international universities. Industry (67\%) includes all nongovernment and nonacademia customers and is by far the largest group.

\section{SWPC Navigation Industry Customers}

The industry customers were further categorized according to the type of company. Figure 2 shows wide-ranging categories that include individuals and companies, both domestic and international. Because a majority of these companies provide GPS services to their own set of customers, they could see tremendous value in space weather products. In general, companies use GPS to improve the safety and efficiency of systems while reducing costs.

For example, precision agriculture uses GPS to assess the existence of in-field variability, and the collective data GPS yields can precisely evaluate sowing density, estimate input needs such as fertilizers, and even accurately predict crop yields. The average input savings per acre is estimated at $\$ 19$ for corn, $\$ 18.50$ for beans, and $\$ 39$ for cotton [Precision Ag Institute, 2008].

In the case of the oil-drilling industry, GPS is critical for positioning. Marking the location of prospective oil strikes requires near-pinpoint accuracy. If GPS is disrupted, it can cost approximately $\$ 1$ million per day to delay operations of oil drilling in the Gulf of Mexico [National Research Council, 2008].

Even the banking industry relies on GPS. GPS satellites are used to time-stamp financial transactions and provide precise time signals for synchronization and fault detection. During bank robberies, GPS devices are thrown into bags of money for tracking and recovery.

\section{Future Direction and Needs}

Since the last solar maximum, the use of GPS capabilities in everyday technology has been on the rise. For example, the use of GPS-enabled mobile phones using the Global System for Mobile Communications (GSM)/Wideband Code Division Multiple Access (W-CDMA) air interface standards is growing fast, especially because the Federal Communications Commission's enhanced 9-1-1 (E9-1-1) emergency call system requires all U.S. mobile operators to provide highaccuracy location of emergency callers by 2012. According to a report by Malm [2010], worldwide shipments of GPSenabled GSM/W-CDMA mobile phones reached 150 million units during 2009, up from 78 million devices in 2008, and are expected to reach 770 million units in 2014. Another recent industry report estimates that the number of subscribers 
of GPS-enabled locationbased services is anticipated to grow substantially in the near future, with market revenue reaching $\$ 10$ billion by 2013 [RNCOS, 2010].

The aviation industry is also expanding its use of GPS for safety and critical location. For example, the Federal Aviation Administration's Next Generation Air Transportation System (NextGen) will modernize air travel and use GPS as the primary means of navigation for all air travel. In particular, Automatic Dependent Surveillance-

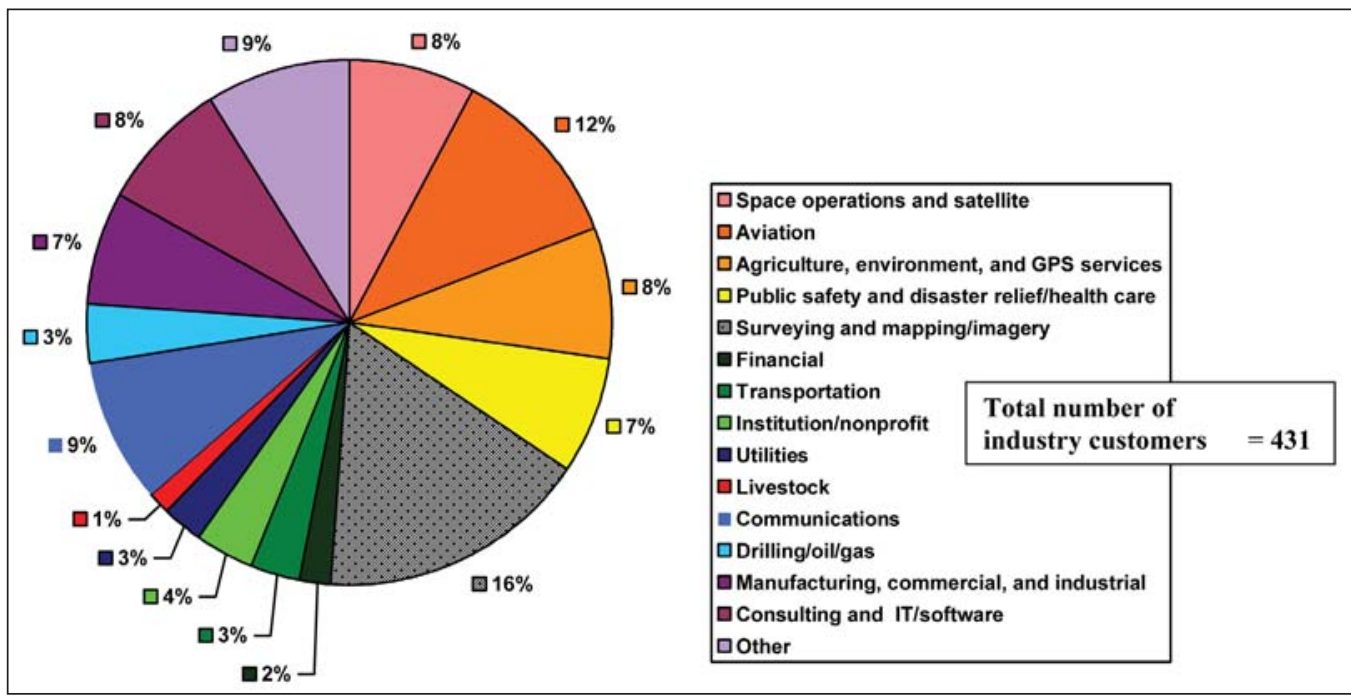

Figure 2. Percentage of Space Weather Prediction Center (SWPC) navigation industry customers by type of company.
Broadcast (ADS-B), a cru-

cial component of NextGen, will provide pilots and air traffic controllers highly accurate traffic data from GPS satellites. In addition, the commercial space transportation industry will depend on GPS for crew and cargo programs and orbital transportation services.

With more and more applications for GPS being discovered, it is expected that disruptions due to space weather will become more apparent to even the occasional user. Therefore, improved predictions of the ionosphere will be even more important. Furthermore, education is needed for the various GPS-reliant industries on how they can use space weather forecasts to mitigate disruptions and improve their operations.

For more information about SWPC products for GPS customers, visit http://www.swpc.noaa.gov/nav/.

\section{Acknowledgments}

This work and J. Meehan's American Meteorological Society summer student fellowship were supported by a U.S. National Science Foundation grant.

\section{References}

Malm, A. (2010), GPS and mobile handsets, 4th ed., Berg Insight, Gothenburg, Sweden. (Available at http://www.berginsight.com/ShowReport .aspx?m_m=3\&Id=97)

National Research Council (2008), Severe Space Weather Events-Understanding Societal and Economic Impacts: A Workshop Report, 144 pp., Washington, D. C.

Precision Ag Institute (2008), Precision Ag works: Lessons from the front line, Meister Media Worldwide, Willoughby, Ohio. (Available at http:// www.gpsfarm.com/LinkClick.aspx?fileticket=NdNZXB4L0RI\%3D \&tabid=98)

RNCOS (2010), World GPS market forecast to 2013, Rep. CICQ2601083, 85 pp., New Delhi. (Available at http://www.rncos.com/Report/IM035 .htm)

Jennifer Meehan is a graduate student at Hampton University, Hampton, Va. Genene Fisher is a senior policy fellow at the American Meteorological Society, Washington, D. C. William Murtagh is a program coordinator for NOAA's Space Weather Prediction Center, Boulder, Colo. 